\title{
A Possibilidade de Saltos no Câmbio Implícita nos Prêmios das Opções*
}

\author{
Bernardo de Vasconcellos Guimarães ${ }^{* *}$ \\ Marcos Eugênio da Silva***
}

Sumário: 1. Introdução; 2. Modelo estimado; 3. Trabalho empírico; 4. Resultados; 5. A credibilidade do regime cambial; 6. Conclusão.

Palavras-chave: opções; taxa de câmbio; saltos; volatilidade.

Códigos JEL: G13.

Neste artigo, são estimados os parâmetros — implícitos nos prêmios das opções - de um modelo de precificação de derivativos que considera a possibilidade de saltos discretos no câmbio (o modelo de Merton), no período entre janeiro de 1997 e janeiro de 1999. Esses parâmetros representam probabilidades e magnitudes esperadas de uma desvalorização do real. Argumenta-se em favor dessas estimativas como medidas de credibilidade do regime de bandas que vigorou de março de 1995 a janeiro de 1999 e apresentam-se evidências de que os smiles de volatilidade encontrados no mercado de câmbio no período são explicados pela possibilidade de saltos discretos. Os resultados obtidos mostram que os momentos de grande desconfiança na moeda correspondem a épocas de crises em outros países e que o salto cambial de janeiro de 1999 superou em muito a magnitude esperada de uma desvalorização do real.

This paper estimates the parameters of a pricing model which considers the possibility of discrete jumps in the Brazilian exchange rate (Merton's model), from January 1997 to January 1999. Those parameters can be seen as probabilities and expected magnitudes of real devaluation. Such estimates are defended as good measures of credibility of the exchange rate policy that prevailed from March 1995 to January 1999, and it is argued that the possibility of discrete jumps explains the existence of volatility smiles for Brazilian exchange rate options during that period. According to the

\footnotetext{
*Este artigo, recebido em ago. 2000 e aprovado em jul. 2001, baseia-se na dissertação de mestrado do primeiro autor, orientado pelo segundo. Os autores agradecem aos participantes de seminários no IME/USP e na FEA/USP, a José Carlos de Souza Santos, Marco Antonio Bonomo, Mauro Rodrigues Jr., Paulo Picchetti e a um parecerista anônimo. Bernardo Guimarães agradece sincera e fortemente a bolsa concedida pelo CNPq. Os erros remanescentes são de inteira responsabilidade dos autores.

${ }^{* *}$ Doutorando em economia na Universidade de Yale, EUA.

${ }^{* * *}$ Professor do Departamento de Economia da FEA/USP.
} 
results presented by this paper, the magnitude of the discrete jump occurred in January 1999 was underestimated by the market and the credibility of the exchange rate policy was mainly affected by crises in other developing countries.

\section{Introdução}

Em março de 1995, foi instituído o regime de bandas sobre a taxa de câmbio, que vigoraria até o início de janeiro de 1999. Durante todo esse período, o preço em reais da moeda americana poderia flutuar dentro de limites dados pelas chamadas minibandas. A distância entre o "teto" e o "piso" da minibanda era de cerca de 0,5\% durante a maior parte desse período (em 1998, essa distância foi-se alargando gradativamente, chegando a estar em torno de 1\%). Além das minibandas, havia também a banda larga, com amplitude próxima de 10\%, que era reajustada cerca de uma vez por ano.

Devido aos resultados negativos da conta corrente do balanço de pagamentos do Brasil, que apontavam a sobrevalorização do real e a conseqüente necessidade de se corrigir essa distorção, o Banco Central reajustava os limites da minibanda em aproximadamente $0,6 \%$ ao mês, durante todo o período. Esses reajustes ocorriam paulatinamente e se distribuíam ao longo do mês. Esperava-se, então, que a moeda nacional alcançasse seu valor real de maneira gradual. Contudo, durante todo o período estudado, era considerada a hipótese de se modificar a política cambial brasileira.

As expectativas dos agentes quanto à sustentabilidade do regime e ao que aconteceria se este fosse rompido se refletiam nos preços das opções e dos contratos futuros de dólar. Neste artigo, busca-se extrair informações referentes à confiança no real implícitas nos prêmios das opções negociadas de janeiro de 1997 a janeiro de 1999, a partir da estimação dos parâmetros de um modelo que possibilita a ocorrência de saltos discretos (o modelo proposto por Merton (1976)). As estimativas obtidas representam probabilidades e magnitudes esperadas de uma desvalorização do real. Argumenta-se que essa metodologia para avaliar a credibilidade do regime é mais adequada e precisa que testes de credibilidade das bandas como os executados em Munch (1998), Fontes et al. (1999) e Campa et al. (1999) e mostra-se que as estimativas obtidas são medidas de confiabilidade melhores que os prêmios de risco dos contratos futuros de dólar.

A estimação de parâmetros implícitos nas opções para mensurar o risco de grandes saltos na trajetória de um ativo foi proposta por Bates (1991), que tenta responder se o crash da bolsa norte-americana em 1987 era esperado. Rocha 
\& Moreira (1998) estimam um dos parâmetros do modelo de Merton para obter informações sobre a credibilidade do regime cambial brasileiro. Campa et al. (1999) analisam a confiança no real a partir de estimações não-paramétricas. Evidências em favor de modelos de precificação de opções que possibilitam saltos discretos na trajetória do ativo podem ser encontradas, por exemplo, em Bates (1996), que incorpora volatilidade estocástica ao modelo, e em Bakshi et al. (1997), que trabalham com volatilidade e taxa de juros estocásticas.

Os resultados obtidos permitem traçar mapas de credibilidade do regime cambial e mostram que a confiança no real dependia fundamentalmente da situação de outros mercados emergentes. Os períodos correspondentes às crises asiática e russa são claramente os momentos de maior risco de desvalorização da moeda brasileira. A magnitude do salto do real, condicional à ocorrência de mudança na trajetória do câmbio, embutida nos valores dos derivativos parece ter sido inferior à que efetivamente ocorreu em janeiro de 1999. Isto significaria que o mercado não foi capaz de traduzir corretamente em preços uma importante variável econômica: o tamanho da maxidesvalorização.

Além de tentar contribuir na avaliação da credibilidade da política cambial vigente no período, este artigo busca explicar a causa dos smiles de volatilidade encontrados no mercado de câmbio brasileiro da época. Smiles de volatilidade são relações empíricas entre volatilidades implícitas (de acordo com o modelo de Black \& Scholes (1973)) e preços de exercício das opções e não fazem parte de qualquer modelo teórico conhecido de precificação de derivativos. A figura 1 mostra um exemplo de smile, calculado utilizando opções negociadas no início de janeiro de 1998, com vencimento dali a um mês.

Figura 1

Smile de volatilidade para o início de jan. 1998

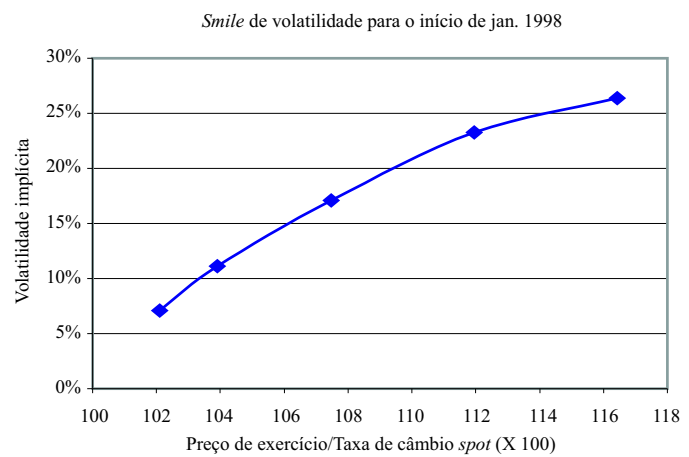


Uma das possíveis razões para a presença dos smiles de volatilidade é que eles mimetizam alguma característica do processo real de difusão do ativo não considerada pelos modelos da família Black \& Scholes (1973). Guimaraes (2000) mostra que há uma regularidade bastante razoável nas relações entre preços de exercício e volatilidades implícitas.

Deve-se destacar que a volatilidade do dólar à vista estimada a partir de séries temporais pelos métodos usuais não ultrapassa em nenhum momento a casa dos $5 \%$ anuais (no período considerado), enquanto as volatilidades implícitas nos preços das opções chegam a mais de $25 \%$, como mostra a figura 1. Este artigo busca mostrar que a possibilidade de saltos discretos é a responsável pela presença dos smiles de volatilidade no mercado em estudo.

A próxima seção descreve o modelo utilizado. A seção 3 trata do trabalho empírico realizado. A seção 4 apresenta e analisa os resultados. A seção 5 aprofunda a discussão sobre a credibilidade do regime cambial vigente no período, restando as conclusões para a seção 6 .

\section{Modelo Estimado}

Em 1976, poucos anos após a divulgação do modelo de Black \& Scholes (1973), Merton (1976) publicaria seu modelo com um processo de difusão permitindo saltos discretos (jumps). A ocorrência desses saltos seguiria uma distribuição de Poisson. A solução para o problema de precificação dependeria, então, da distribuição de probabilidades da magnitude do salto e só haveria soluções analíticas em alguns casos particulares. O modelo considerado neste artigo é um desses casos particulares, em que a magnitude do salto obedece a uma distribuição de probabilidades log-normal. O processo de difusão considerado é:

$$
\frac{d S}{S}=(b-\lambda k) d t+\sigma d Z+J d q
$$

onde:

$S$ é a taxa de câmbio spot: ${ }^{1}$

$b$ é a desvalorização cambial esperada;

$\sigma$ é a volatilidade da taxa cambial, na ausência de saltos;

$d Z$ é um processo browniano;

$\lambda$ é o parâmetro de média da distribuição de Poisson (ocorrência do salto);

$J$ é a magnitude do salto (condicional a $d q=1$ ), tal que

\footnotetext{
${ }^{1} \mathrm{~A}$ taxa do câmbio spot é a cotação do dólar à vista.
} 


$$
(1+J) \sim \log -\operatorname{Normal}(\mu j, \sigma j)
$$

sendo

$\mu j$ a média da distribuição normal associada;

$\sigma j$ é o desvio padrão da distribuição normal associada;

$d q$ é o número de saltos em um período de tempo dt, de modo que

$$
\begin{array}{r}
d q=0 \text { com probabilidade } 1-\lambda d t \\
d q=1 \text { com probabilidade } \lambda d t
\end{array}
$$

$d Z, J$ e $d q$ são considerados independentes.

A esperança da magnitude do salto condicional à sua ocorrência é dada por:

$$
k=E(J)=\exp \left(\mu j+\frac{\sigma j^{2}}{2}\right)-1
$$

A esperança não-condicional do salto (equivalente ao prêmio de risco embutido nos preços) é igual a $\lambda k$ (em termos anuais). A volatilidade (desvio-padrão dos retornos) do componente referente ao salto é dada por:

$$
D P J=\sqrt{\lambda\left(k^{2}+e^{\left(\sigma j^{2}-1\right)}\left(1+k^{2}\right)\right)}
$$

Há quatro variáveis não-observáveis influindo no prêmio da opção: a volatilidade $(\sigma)$, a média e o desvio-padrão da distribuição referente à magnitude do salto $(\mu j$ e $\sigma j)$ e a média da distribuição de Poisson referente ao número de saltos $(\lambda)$. De acordo com esse modelo, o agente considera não só a volatilidade da taxa de câmbio, mas também a possibilidade de saltos discretos — alterações na política cambial.

Uma das hipóteses utilizadas em Merton (1976) é a de que o risco de um salto é não-sistemático, dado por informações novas, não-correlacionado com as informações disponíveis no mercado. Isto é pouco plausível no contexto deste artigo. Bates (1991) descarta essa hipótese e, assumindo que a função de utilidade do agente representativo é separável no tempo e postulando aversão relativa ao risco constante (CRRA), demonstra que os derivativos são precificados como se os investidores fossem neutros ao risco e o processo de difusão seguido pelo ativo fundamental fosse: 


$$
\frac{d S}{S}=\left(b-\lambda^{*} k^{*}\right) d t+\sigma d Z+J^{*} d q^{*}
$$

onde $\lambda^{*}, k^{*}$ e $J^{*}$ são os parâmetros ajustados ao risco, que consideram variações na utilidade marginal do consumidor representativo.

Como não existe a possibilidade de se fazer um hedge perfeito contra o salto, a posição do agente em relação ao risco influi no preço da opção. Sob a hipótese de neutralidade ao risco, o modelo desenvolvido por Bates (1991) se reduz ao modelo de Merton. ${ }^{2}$

\section{Trabalho Empírico}

O intuito deste artigo não é estimar as volatilidades, probabilidades e médias "reais" implícitas do processo de difusão, mas seus valores sob a hipótese de neutralidade ao risco. Inferir os parâmetros "verdadeiros" requereria hipóteses adicionais sobre o grau de aversão ao risco do agente representativo e sobre o impacto de uma variação discreta da cotação do câmbio em sua riqueza. Dado que uma desvalorização da moeda nacional torna o agente mais pobre, temos que, se os agentes são avessos ao risco, os prêmios das opções tendem a ser maiores que os de um outro mercado com os mesmos fundamentos (ou seja, mesmos valores de $\sigma j, \lambda$ e $\mu j$ ) e agentes neutros ao risco. Ou seja, sendo os agentes avessos ao risco e dado que para se proteger de eventuais saltos na cotação cambial deve-se comprar opções de compra (ou futuros), temos que os prêmios de equilíbrio destas devem ser superiores aos esperados em um mercado composto por agentes neutros ao risco, assim como a probabilidade de um carro ser roubado implícita no preço do seguro é maior que a probabilidade "real" estimada pela seguradora. Conseqüentemente, os parâmetros $\lambda$ e $k$ implícitos nos prêmios observados tendem a ser mais altos que os reais valores referentes às probabilidades e magnitudes dos saltos. ${ }^{3}$

Há opções vencendo no primeiro dia útil de todos os meses. Para cada vencimento, o modelo foi estimado de dois modos:

No modo 1 , há $2 T+2$ parâmetros a serem estimados por vencimento:

\footnotetext{
${ }^{2}$ As fórmulas para o preço das opções dos modelos de Bates (1991) e de Merton (1976) são bastante semelhantes. A única diferença é que os parâmetros que entram na fórmula de Bates não são as reais probabilidades e magnitudes esperadas de um salto: são valores destas ajustados ao risco e, portanto, dependem da função utilidade do agente representativo.

${ }^{3}$ Rocha \& Moreira (1998) chegam à conclusão de que $\lambda$ é positivamente correlacionado com o grau de aversão ao risco porque supõem relações positivas entre o salto na cotação cambial e o grau de riqueza do agente. Considerando que o agente fica mais pobre quando sua moeda se desvaloriza, deve ser obtida a relação inversa (Bates, 1991, 1996).
} 
- um parâmetro $k$;

- um parâmetro $\sigma j$;

- para cada dia, um $\sigma$ (portanto, $T \sigma$ );

- para cada dia, um $\lambda$ (portanto, $T \lambda$ ).

No modo 2, há $T+3$ parâmetros a serem estimados por vencimento:

- um parâmetro $k$;

- um parâmetro $\sigma j$;

- um parâmetro $\sigma$,

- para cada dia, um $\lambda$ (portanto, $T \lambda$ )

Assume-se que reestimação diária de alguns dos parâmetros do modelo é potencialmente inconsistente com a hipótese de parâmetros constantes, utilizada para se derivar o modelo de precificação de opções. Procedimentos semelhantes foram seguidos por Rocha \& Moreira (1998), Bates (1991, 1996) e Bakshi et al. (1997) e se justificam por:

- gerarem uma cronologia dos parâmetros e do sentimento do mercado;

- gerarem fatos estilizados para análises econômicas;

- captarem diariamente as mudanças ocorridas nas expectativas do mercado, ainda que de maneira ad hoc.

É possível interpretar os resultados obtidos considerando que o agente se depara, diariamente, com duas possibilidades:

- o câmbio pode continuar sua trajetória de desvalorização lenta, com um drift $(b-\lambda k)$ e volatilidade $\sigma$

- o câmbio pode saltar para um outro patamar - esse salto é distribuído como uma log-normal, e os parâmetros que descrevem a distribuição de probabilidades de sua magnitude ( $k$ e $j$ ) são constantes até o vencimento da opção; a probabilidade desse salto ocorrer é descrita por uma Poisson, com média $\lambda$ por ano. 
De acordo com variações no cenário econômico (ou, enfim, em quaisquer outros fatores relevantes), a volatilidade $(\sigma)$ e a probabilidade de mudança de patamar $(\lambda)$ percebidas pelos agentes vão-se alterando e os prêmios das opções vão-se modificando. O objetivo, aqui, é estimar os fatores que "ditam" os prêmios, a partir desse modelo $\left(k, \sigma j, \sigma_{1}, \ldots, \sigma_{t}, \ldots, \sigma_{T}, \lambda_{1}, \ldots, \lambda_{t}, \ldots, \lambda_{T}\right)$.

A probabilidade de mudança de patamar, associada ao parâmetro $\lambda$, é reestimada dariamente por entendermos que esta variável é fortemente influenciada por fatores que podem sofrer alterações bruscas em pouco tempo, como a conjuntura política e a situação dos mercados internacionais. Dado que ocorreu o salto, a distribuição de probabilidades de sua magnitude deve depender de parâmetros estruturais da economia. Assim, estimamos apenas um par de variáveis $k$ e $\sigma j$ por vencimento.

A volatilidade $(\sigma)$ está relacionada com as variações cambiais ocorridas durante a trajetória de desvalorização lenta do real. Portanto, não é um indicador de credibilidade do regime e deve depender de fatores como a estabilidade dos fluxos cambiais no curto prazo. Em tese, a volatilidade poderia alterar-se substancialmente em poucos dias. No período em estudo, porém, as minibandas davam pouco espaço para esses movimentos. Considerando, então, a escassez de dados e as dificuldades econométricas envolvidas neste artigo, faz sentido estimar apenas um parâmetro $\sigma$ por vencimento para obtermos estimativas mais precisas. Por outro lado, variações não-controladas da volatilidade poderiam enviesar os estimadores dos demais parâmetros. Assim, optou-se por estimar o modelo de duas maneiras diferentes, variando-se diariamente o parâmetro $\sigma$ no modo 1 e estimando-se apenas um $\sigma$ por vencimento no modo 2 .

Para que seja possível estimar estatisticamente os parâmetros de um modelo, é preciso que exista algum componente aleatório. Assim, assumiu-se que o preço de uma opção de compra é dado por: ${ }^{4}$

$$
\operatorname{PMerc}_{x t}=\operatorname{PMod}_{x t}\left(S_{t}, b_{t}, r_{t}, \tau_{t}, X, k, \sigma j, \sigma_{t}, \lambda_{t}\right)+\epsilon_{x t}
$$

onde:

$P M e r c_{x t}$ é o prêmio de mercado de uma opção com strike $x$, no dia $t$ (dado); $P_{\text {od }}$ xt é o prêmio da opção com strike $x$ no dia $t$, de acordo com a fórmula do modelo de Merton (apresentada na seção 2); ${ }^{5}$

\footnotetext{
${ }^{4}$ As fórmulas a seguir referem-se ao modo 1 de estimação. Ao trabalhar-se com apenas um $\sigma$ por vencimento, obtêm-se, de maneira análoga, as fórmulas para o modo 2 .

${ }^{5}$ A fórmula para o cálculo do prêmio da opção de acordo com o modelo de Merton $\left(P M o d_{x t}\right)$ contém uma somatória em que o número de saltos $(n)$ varia de 0 a infinito. As rotinas computacionais trabalharam com uma somatória de 0 a 4 - porque incluir a possibilidade de cinco ou mais
} 
$\epsilon_{x t}$ é o erro aleatório.

O objetivo é encontrar os valores de $k$ e $\sigma j$ e os valores diários de $\sigma$ e $\lambda$ que minimizam o quadrado das diferenças entre os prêmios observados das opções e os prêmios dados pelo modelo de Merton. Sendo $e_{x t}$ o resíduo da regressão, ou seja, a diferença entre o preço observado e o preço dado pelo modelo teórico e considerando que devem ser estimados um valor de $\sigma$ e de $\lambda$ para cada dia e apenas um valor de $k$ e de $\sigma j$, temos que: ${ }^{6}$

$$
e_{x t}=f\left(k, \sigma j, \sigma_{t}, \lambda_{t}\right)
$$

e, conseqüentemente,

$$
S Q R=f\left(k, \sigma j, \sigma_{1}, \ldots, \sigma_{t}, \ldots, \sigma_{T}, \lambda 1, \ldots, \lambda_{t}, \ldots, \lambda_{T}\right)
$$

sendo $T$ o número de dias da amostra e $t$ o indexador dos dias.

Portanto, nosso problema é encontrar os parâmetros que satisfazem:

$$
S Q R=\operatorname{Min}_{\left(k, \sigma j, \sigma_{1}, \sigma_{2}, \ldots, \sigma_{T}, \lambda_{1}, \lambda_{2}, \ldots, \lambda_{T}\right)} \sum_{t=1}^{T} \sum_{x=1}^{n x} e_{x t}^{2}
$$

sendo $n x$ o número de opções com diferentes preços de exercício negociadas em um dia.

Havendo vários dias de negociação na amostra, pode ser computacionalmente difícil trabalhar com um problema de otimização sob um número tão grande de variáveis. $^{7}$ Nesses casos, torna-se vantajoso transformar o problema acima, de forma que o objetivo seja encontrar:

$$
S Q R=\operatorname{Min}_{(k, \sigma j)} \sum_{t=1}^{T} \operatorname{Min}_{\left(\sigma_{t}, \lambda_{t}\right)} \sum_{x=1}^{n x}\left(e_{x t} \mid k, \sigma j\right)^{2}
$$

saltos até o vencimento das opções não modificava o valor dos prêmios, mesmo nos momentos de maior risco de desvalorização do real.

${ }^{6} \mathrm{~A}$ variável $e_{x t}$ é, evidentemente, função também das variáveis observáveis que entram no cálculo do prêmio da opção (citadas anteriormente). Formalmente, temos $e_{x t}=f\left(k, \sigma j, \sigma_{t}, \lambda_{t} \mid b, r, S, \tau, X, P M e r c_{x t}\right)$, mas omitiremos as variáveis observáveis nesta seção para não carregarmos demais a notação.

${ }^{7}$ Esta observação vale principalmente para o modo 1 de estimação. 
Obtém-se, assim, um problema de minimização de quadrados dos resíduos cuja função-objetivo depende do resultado de outras $T$ otimizações não-lineares.

As duas formas de estimar o problema são equivalentes para encontrarmos os parâmetros do modelo de Merton implícitos nos prêmios das opções. Contudo, os erros dos coeficientes devem ser calculados utilizando os gradientes obtidos na estimação com todas as variáveis simultaneamente, porque, na segunda forma apresentada, as derivadas obtidas não são parciais.

As opções com maiores preços de exercício são mais baratas e, portanto, um erro de 0,10 numa opção "fora do dinheiro" pode ser considerado mais significativo que um erro de 0,10 numa opção de menor preço de exercício. Uma alternativa para contornar este problema seria ponderar os erros. Em trabalhos semelhantes ao apresentado neste artigo, Bates $(1991,1996)$ e Bakshi et al. (1997) preferiram não utilizar qualquer critério de ponderação — procedimento seguido aqui. ${ }^{8}$

O trabalho empírico utilizou as rotinas de otimização do software Matlab, baseadas em algoritmos de minimização de quadrados de funções não-lineares (Levenberg-Marquardt, Gauss-Newton) ou de busca direta (método simplex ameba - de Nelder-Mead). Estimações referentes a alguns dos vencimentos só foram possíveis por utilizarmos o algoritmo simplex. ${ }^{9}$ Os valores que minimizavam a soma dos quadrados dos resíduos de acordo com este método eram colocados como condições iniciais nos algoritmos de mínimos quadrados para verificar o resultado e calcular a matriz de variância e covariância dos estimadores.

A soma do quadrado dos resíduos de modelos não-lineares pode ter mais de um mínimo local. Para buscar o mínimo global, cada vencimento foi estimado a partir de diferentes condições iniciais. Na grande maioria das vezes, os algoritmos convergiam em torno do mesmo ponto e as diferenças entre as estimativas obtidas eram inferiores a $10^{-3}$. Entre as exceções, há algumas grandes discrepâncias, como fevereiro de 1998 no modo 1 (um mínimo com $k$ próximo de $3 \%$ e outro com $k$ em torno de $13 \%$ ) e março de 1998 no modo 2 (um mínimo com $k$ próximo de $7 \%$ e outro com $k$ negativo, em torno de $-7 \%$ ). Em outros casos, como dezembro de 1997 no modo 1 e setembro de 1997 no modo 2, a distância entre as estimativas do parâmetro $k$ em diferentes pontos de mínimo local é menor que $1 \%$, ainda que não desprezível.

Os dados utilizados para as estimações (valores das opções de compra, futuros de dólar e DI e taxa de câmbio spot, de janeiro de 1997 a janeiro de 1999) foram

\footnotetext{
${ }^{8}$ Bakshi e outros (1997) argumentam que minimizar o erro percentual levaria a um "favorecimento" das opções fora do dinheiro. Bates (1991) utiliza justificativa similar para trabalhar com erros aditivos, em vez de multiplicativos.

${ }^{9}$ Estimações para janeiro de 1998, por exemplo, não convergem se forem utilizadas apenas rotinas de minimização de quadrados de funções não-lineares.
} 
fornecidos pela Bolsa de Mercadorias \& Futuros (BM\&F). O prêmio utilizado das opções foi o último negócio de cada dia. Como é pequeno o número de transações diárias desse mercado, os negócios com as opções utilizados neste artigo são potencialmente realizados em horários diferentes. ${ }^{10}$ Em dias de grandes oscilações, essa falta de sincronia pode trazer distorções aos nossos dados. Isso explica o fato de termos eventualmente, aqui, prêmios de certas opções maiores ou iguais aos de outras com preços de exercício menor. ${ }^{11}$

Os dados de DI futuro e dólar futuro utilizados foram os preços de ajuste. Esses valores são as médias dos preços dos negócios nos últimos minutos do pregão (ponderados pelos volumes). O tempo foi calculado em dias corridos ( $\tau=$ número de dias corridos $\div 360)$. O dólar futuro foi utilizado para o cálculo da taxa de juros em moeda estrangeira (taxa do $D I \div$ variação projetado do dólar).

As taxas de juros são calculadas sempre de maneira contínua (por exemplo, $r=\ln (100.000 / D I) \div \tau)$. Para a taxa cambial spot havia, basicamente, duas opções: considerar o ptax ${ }^{12}$ do dia anterior (e implicitamente admitir que o agente não sabe nada sobre o valor do dólar no dia) ou considerar o ptax do dia (e implicitamente admitir que o operador já conhece a cotação média daquele dia). Por estarmos trabalhando com os últimos negócios de opções, optamos pela segunda abordagem. Coerentemente com essa escolha, foi considerado para o cálculo do tempo para o vencimento das opções o dia útil imediatamente anterior à data de liquidação das operações, visto que estas tomam como base o ptax do dia anterior.

As opções com uma determinada data de vencimento são tratadas independentemente das outras. Depois de separarem-se as opções por vencimento, excluem-se da amostra:

- as informações referentes aos dias em que não foram negociadas opções com pelo menos cinco preços de exercícios diferentes, para termos graus de liberdade suficientes para uma estimação razoável.

- as informações referentes aos dias muito próximos ao vencimento, dada a pequena liquidez destas opções e o pequeno impacto destas na soma do quadrado dos erros do modelo.

\footnotetext{
${ }^{10} \mathrm{~A}$ BM\&F divulga o horário do último negócio com cada opção. Contudo, este indicador não é muito preciso, dado que negócios com opções são realizados no mercado de balcão e, depois de fechada a operação, simulados pelos operadores de pregão na bolsa — onde a operação é registrada. Às vezes, isso se dá horas depois de a operação ser fechada.

${ }^{11}$ Descartar esses dados da amostra traria um viés de seleção para nossos estimadores, por aumentar a diferença média amostral entre os preços das opções com diferentes preços de exercício em um dado dia — informação fundamental para se estimarem os parâmetros $k$ e $\sigma j$.

${ }^{12} \mathrm{O}$ ptax é a cotação média das transações de câmbio no mercado interbancário (à vista).
} 
Foram também excluídos da amostra alguns poucos dados de opções muito "fora do dinheiro" (mais de 30\% acima do spot) de março, abril e agosto de 1998, cujos valores são estatisticamente outliers.

Devido à pequena liquidez no mercado de opções, há muito poucos dados para alguns dos vencimentos, o que pode prejudicar bastante a precisão do estimador. Esse problema é acentuado pelo fato de estarmos estimando um grande número de parâmetros para cada vencimento. A tabela 1 mostra a quantidade de dados utilizada para as estimações.

Tabela 1

Dados utilizados para as estimativas

\begin{tabular}{|c|c|c|c|c|}
\hline Veto & ndias & nobs & $N(1)$ & $N($ Q) \\
\hline Fev. 1997 & 7 & 45 & 16 & 10 \\
\hline Mar. 1997 & 11 & 64 & 24 & 14 \\
\hline Abr. 1997 & 25 & 134 & 52 & 28 \\
\hline Maio 1997 & 9 & 45 & 20 & 12 \\
\hline Jun. 1997 & 7 & 38 & 16 & 10 \\
\hline Jul. 1997 & 48 & 269 & 98 & 51 \\
\hline Ago. 1997 & 5 & 26 & 12 & 8 \\
\hline Set. 1997 & 13 & 67 & 28 & 16 \\
\hline Out. 1997 & 33 & 185 & 68 & 36 \\
\hline Nov. 1997 & 16 & 85 & 34 & 19 \\
\hline Dez. 1997 & 26 & 144 & 54 & 29 \\
\hline Jan. 1998 & 18 & 107 & 38 & 21 \\
\hline Fev. 1998 & 18 & 97 & 38 & 21 \\
\hline Mar. 1998 & 6 & 31 & 14 & 9 \\
\hline Abr. 1998 & 13 & 72 & 28 & 16 \\
\hline Maio 1998 & 19 & 106 & 40 & 22 \\
\hline Jun. 1998 & 22 & 135 & 46 & 25 \\
\hline Jul. 1998 & 18 & 119 & 38 & 21 \\
\hline Ago. 1998 & 15 & 95 & 32 & 18 \\
\hline Set. 1998 & 25 & 173 & 52 & 28 \\
\hline Out. 1998 & 28 & 155 & 58 & 31 \\
\hline Nov. 1998 & 16 & 101 & 34 & 19 \\
\hline Dez. 1998 & 12 & 76 & 26 & 15 \\
\hline Jan. 1999 & 15 & 97 & 32 & 18 \\
\hline Fev. 1999 & 6 & 33 & 14 & 9 \\
\hline
\end{tabular}

Obs.: Vcto = vencimento da opção;

ndias = número de dias que compõem a amostra; nobs = número de observações (tamanho da amostra);

$N(1)=$ número de parâmetros estimados no modo 1 ;

$N(2)=$ número de parâmetros estimados no modo 2 . 


\section{Resultados}

Os resultados obtidos para $k$ e $\sigma j$ nos modos 1 e 2 , bem como o erro-padrão dos estimadores e os níveis de significância de acordo com os testes $t$ estão apresentados nas tabelas 2 e 3 .

As figuras 2 e 3 mostram a evolução das estimativas do parâmetro $k$. Gráficos com as estimativas do parâmetro $\lambda$ (no modo 1) estão apresentados no apêndice A.

Figura 2

Estimativas de magnitude esperada do salto $(k)$ - modo 1

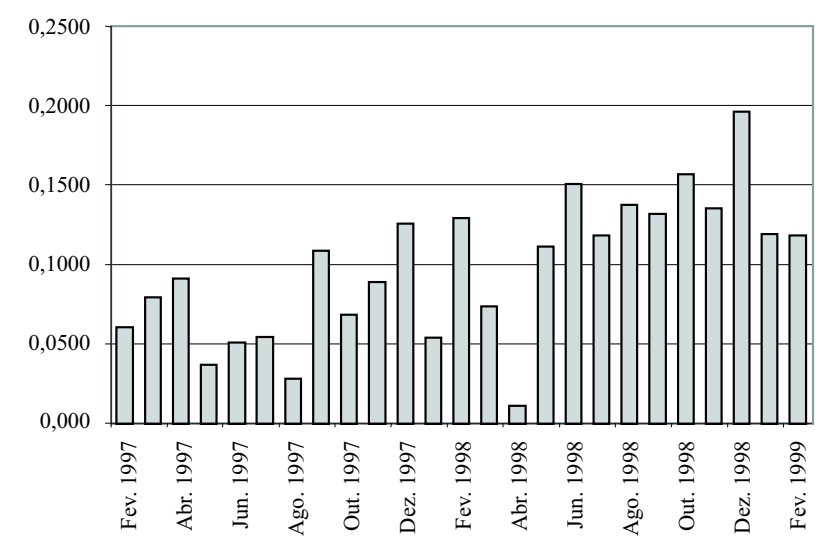

Figura 3

Estimativas de magnitude esperada do salto $k$ - modo 2

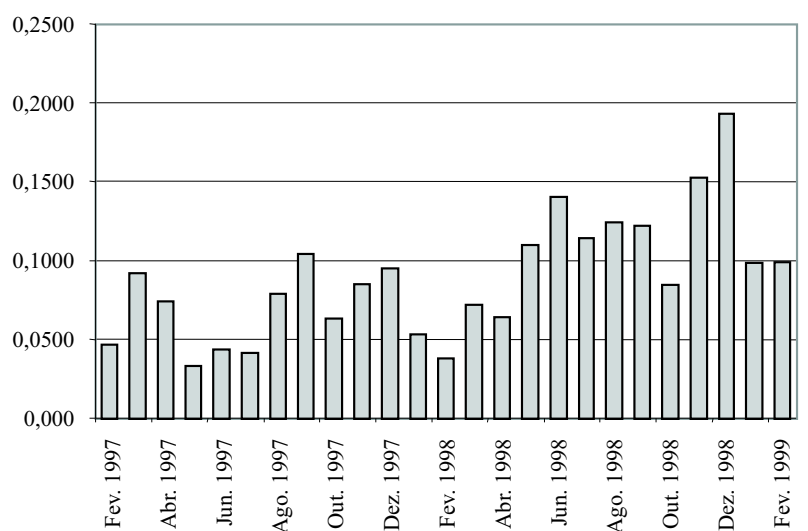


Tabela 2

Estimativas de $\sigma j$ e $k$ e resultado dos testes: modo 1

\begin{tabular}{clllll}
\hline \multicolumn{1}{c}{$K c t o$} & \multicolumn{4}{c}{$\sigma j$} & $p-$ value \\
\hline $02 / 97$ & 0,0601 & $(0,0426)$ & $0,0584^{1}$ & $(0,0200)$ & $4,7 E-19$ \\
$03 / 97$ & $0,0791^{2}$ & $(0,0300)$ & $0,1082^{1}$ & $(0,0162)$ & $9,5 E-36$ \\
$04 / 97$ & $0,0911^{1}$ & $(0,0209)$ & $0,0733^{1}$ & $(0,0126)$ & $2,8 E-65$ \\
$05 / 97$ & 0,0370 & $(0,0785)$ & 0,0508 & $(0,0374)$ & $6,4 E-20$ \\
$06 / 97$ & $0,0506^{2}$ & $(0,0242)$ & $0,0494^{1}$ & $(0,0146)$ & $1,1 E-16$ \\
$07 / 97$ & $0,0542^{2}$ & $(0,0228)$ & $0,0536^{1}$ & $(0,0116)$ & $6,1 E-153$ \\
$08 / 97$ & 0,0279 & $(0,2124)$ & 0,1095 & $(0,0871)$ & $4,6 E-13$ \\
$09 / 97$ & $0,1088^{2}$ & $(0,0520)$ & 0,0552 & $(0,0488)$ & $4,1 E-21$ \\
$10 / 97$ & 0,0683 & $(0,0598)$ & $0,0716^{2}$ & $(0,0315)$ & $6,1 E-71$ \\
$11 / 97$ & $0,0892^{2}$ & $(0,0369)$ & $0,0600^{2}$ & $(0,0244)$ & $1,4 E-39$ \\
$12 / 97$ & $0,1256^{2}$ & $(0,0601)$ & 0,0645 & $(0,0557)$ & $3,0 E-36$ \\
$01 / 98$ & 0,0536 & $(0,0706)$ & $0,0926^{1}$ & $(0,0305)$ & $1,5 E-56$ \\
$02 / 98$ & $0,1294^{1}$ & $(0,0145)$ & $0,0678^{1}$ & $(0,0097)$ & $5,0 E-62$ \\
$03 / 98$ & 0,0732 & $(0,6988)$ & 0,1775 & $(0,2942)$ & $2,9 E-16$ \\
$04 / 98$ & $0,0112^{2}$ & $(0,0048)$ & $0,1393^{1}$ & $(0,0086)$ & $2,9 E-39$ \\
$05 / 98$ & $0,1115^{1}$ & $(0,0165)$ & $0,0669^{1}$ & $(0,0144)$ & $6,8 E-64$ \\
$06 / 98$ & $0,1508^{1}$ & $(0,0405)$ & $0,0858^{1}$ & $(0,0302)$ & $4,3 E-63$ \\
$07 / 98$ & 0,1184 & $(0,0730)$ & $0,1090^{2}$ & $(0,0418)$ & $2,4 E-55$ \\
$08 / 98$ & 0,1373 & $(0,1052)$ & 0,0954 & $(0,0738)$ & $4,6 E-51$ \\
$09 / 98$ & $0,1320^{2}$ & $(0,0551)$ & 0,0612 & $(0,0614)$ & $1,5 E-71$ \\
$10 / 98$ & $0,1568^{2}$ & $(0,0640)$ & 0,0555 & $(0,1547)$ & $8,7 E-56$ \\
$11 / 98$ & $0,1350^{1}$ & $(0,0149)$ & $0,1040^{1}$ & $(0,0104)$ & $8,5 E-49$ \\
$12 / 98$ & $0,1962^{1}$ & $(0,0586)$ & 0,0860 & $(0,0672)$ & $1,5 E-37$ \\
$01 / 99$ & $0,1192^{1}$ & $(0,0148)$ & $0,1383^{1}$ & $(0,0101)$ & $1,8 E-58$ \\
$02 / 99$ & 0,1183 & $(0,0718)$ & 0,0875 & $(0,0462)$ & $8,9 E-16$ \\
\hline${ }^{*}$ p-value dos testes conjuntos, sendo $H_{0}: \mu j=\sigma j=\lambda_{t}=0$ para todo $t$. \\
1 Parâmetro significante a 1\%,de acordo com os testes t. & \\
2 Parâmetro significante a 5\%,de acordo com os testes t. & \\
Desvios-padrão entre parênteses. & & & \\
& & & & &
\end{tabular}


Tabela 3

Estimativas de $\sigma j$ e $k$ e resultado dos testes: modo 2

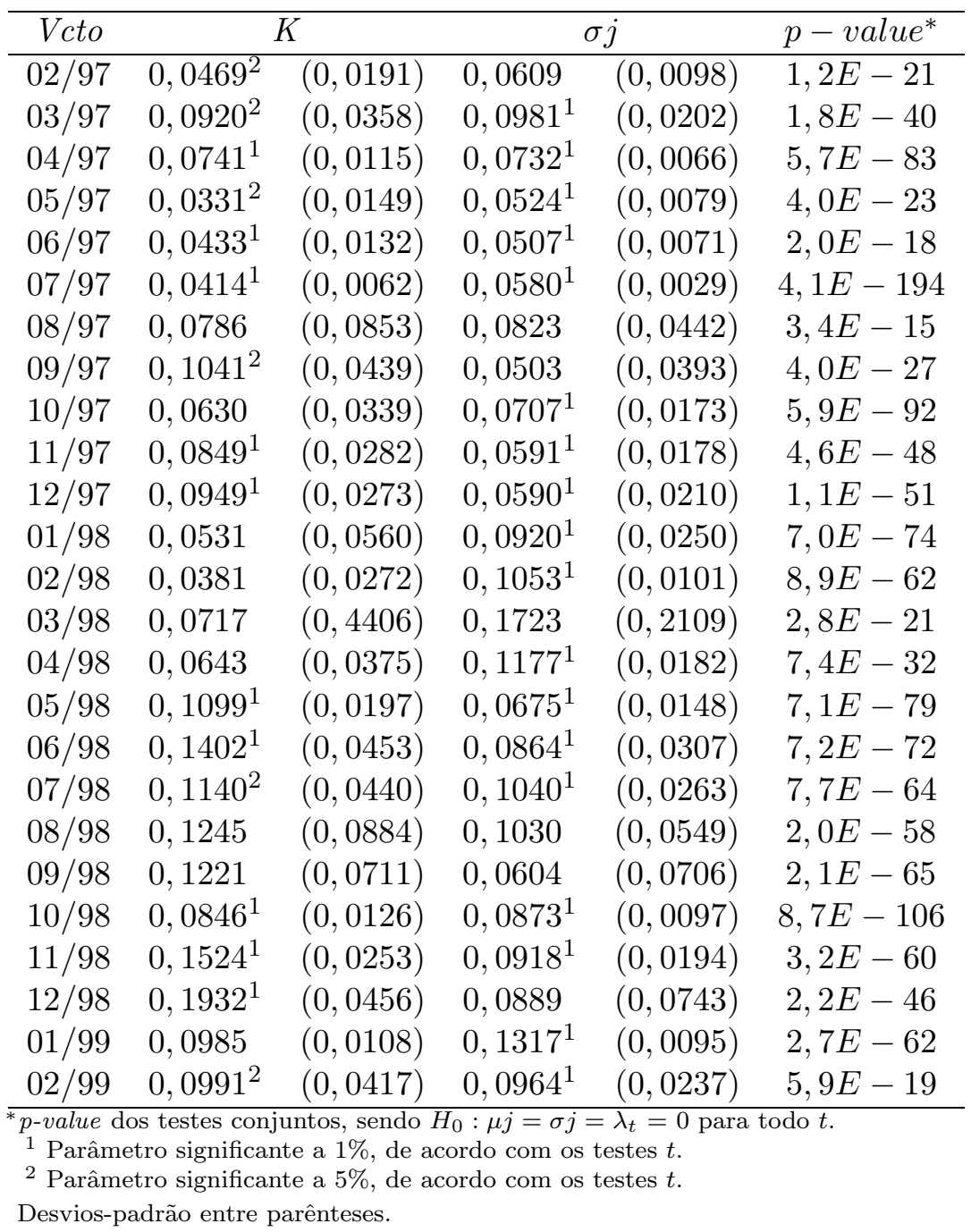

Como seria de se esperar, os erros-padrão obtidos pelo modo 2 de estimação são, em geral, inferiores aos encontrados pelo modo $1 .{ }^{13}$

\footnotetext{
${ }^{13}$ Entre os 50 parâmetros $k$ e $\sigma j$ estimados, há 36 estimativas significativamente diferentes de 0 no modo 2 e 31 no modo 1 . Entre os 50 erros-padrão calculados, 37 são menores no modo 2 do que no modo 1 .
} 
Os resultados obtidos das duas maneiras são parecidos e levam às mesmas interpretações sobre a credibilidade do regime cambial.

Os valores de $k$ obtidos pelo modo 2 são quase sempre inferiores aos encontrados pelo modo 1 (há apenas quatro exceções entre as 25 estimativas), levantando a suspeita de que estimar apenas um $\sigma$ por vencimento poderia enviesar os estimadores dos demais parâmetros. De fato, como mostra a simulação de Monte Carlo apresentada no anexo B, variações não-controladas da volatilidade tendem a causar subestimação do parâmetro $k$ e superestimação do parâmetro $\lambda$. Por conta disso, toda a análise realizada a partir daqui refere-se ao modo 1 de estimação. ${ }^{14}$

Não se observam diferenças substanciais entre os valores obtidos para o parâmetro $k$ em momentos de crise e em tempos tranqüilos; há, contudo, grandes variações em $\lambda$. Pode-se perceber que a magnitude esperada da desvalorização cambial aumenta no decorrer do período. Antes de a crise da Ásia contagiar os mercados brasileiros de derivativos cambiais, em outubro de 1997, a variável $k$ oscila em torno de $7 \%$. Após a crise, $k$ passa a estar predominantemente entre $10 \%$ e $15 \%$ e $\sigma j$ aumenta também.

Os parâmetros referentes à magnitude do salto implícitos nas opções foram constantemente inferiores ao que a realidade revelou, em janeiro de 1999: a expectativas de salto com médias sempre inferiores a $20 \%$ e desvios-padrão estimados em torno de $10 \%$ nos meses que antecederam à maxidesvalorização do real, contrapôsse uma alta de mais de $60 \%$ na cotação cambial. A esta informação, soma-se o fato de os estimadores de $\lambda$ e $k$ terem sido obtidos de um agente neutro ao risco. Como já foi colocado, considerando-se a aversão dos agentes ao risco, deve-se acreditar que os verdadeiros valores de $\lambda$ e $k$ implícitos nos prêmios das opções sejam até menores do que os obtidos.

A probabilidade de um salto no câmbio (dada pelo parâmetro $\lambda$ ) oscila entre 1\% e 3\% ao mês do início de 1997 até o final de outubro, com exceção de um breve período no final de agosto, quando os primeiros reflexos dos problemas no Sudeste da Ásia levam essa taxa para perto de 5\%. Em novembro de 1997, no auge da crise asiática, a probabilidade de uma desvalorização fica em torno de $10 \%$ ao mês. Em dezembro, essa taxa já está bem mais baixa, e em fevereiro de 1998 observa-se $\lambda$ nos níveis pré-crise. A partir da crise russa, em setembro de 1998, até a alteração do regime cambial, em janeiro de 1999, a probabilidade do salto flutua em torno de $5 \%$ ao mês.

A estimação dos parâmetros $k, \lambda$ e $\sigma j$ para alguns vencimentos (como abril de 1998 no modo 1) parece ter sido prejudicada pela inexistência de dados sobre

\footnotetext{
${ }^{14}$ Embora potencialmente tendenciosas, as estimativas obtidas pelo modo 2 também merecem atenção por serem mais precisas e porque o viés não deve ser grande.
} 
opções "no dinheiro" ou "dentro do dinheiro". Essas opções trariam informações relevantes sobre a possibilidade (praticamente nula) de apreciação do real, influindo no valor das estimativas obtidas.

O estimador da variância dos erros foi obtido dividindo-se a soma do quadrado dos resíduos pelo número de graus de liberdade da regressão $(N-k ; k=$ $2 \underline{T}+2$ no modo $1, k=T+3$ no modo 2 ) conforme recomendação de Davidson \& MacKinnon (1993) baseada "no bom senso e em experimentos de Monte Carlo".

Os resultados dos testes individuais (testes $t$ bilaterais) devem ser analisados com bastante cautela, pois os pressupostos implícitos em sua execução - por exemplo, a suposição de que o estimador dos parâmetros é normalmente distribuído — são muito fortes. Além disso, quando estamos interessados na significância de vários parâmetros, testá-los individualmente pode-nos levar a conclusões equivocadas. Assim, foram executados testes "pseudo- $F$ " 15 para verificar a significância do conjunto de parâmetros referentes aos saltos, comparando-se os resultados fornecidos utilizando-se o modelo de Merton (irrestrito) com os obtidos impondo-se as restrições:

$$
\lambda_{t}=k=\sigma j=0, \text { sendo } 1 \leq t \leq T
$$

O resultado dos testes está apresentado também nas tabelas 2 e 3 .

Enquanto os testes conjuntos nos mostram que as restrições sobre os parâmetros referentes aos saltos têm graus de significância entre $10^{-13}$ e $10^{-194}$ (tabelas 2 e 3 ), os testes individuais apresentam resultados muito menos significativos, às vezes até insignificantes, ${ }^{16}$ Por exemplo, nenhum dos parâmetros obtidos para o vencimento em março de 1998 (14 no modo 1 e nove no modo 2) é significantemente diferente de zero, mesmo a um nível de significância de 10\%. Todavia, os p-values dos testes conjuntos $\left(3 \times 10^{-16}\right.$ no modo 1 e $3 \times 10^{-21}$ no modo 2$)$ mostram inequivocamente que a possibilidade de saltos discretos tem efeito significativo nos preços das opções.

Os resultados desses testes ressaltam a existência de um problema de identificação deste modelo com os dados disponíveis: em alguns momentos é difícil estimar a média e o desvio-padrão da magnitude do salto e a probabilidade de sua ocorrência, embora seja fácil perceber a influência da possibilidade de saltos discretos no prêmio das opções.

\footnotetext{
${ }^{15}$ Os testes "pseudo-F" são assim denominados (Davidson \& MacKinnon, 1993) por serem executados da mesma maneira que os testes $F$ mas valerem apenas assintoticamente no caso de modelos não-lineares.

${ }^{16}$ Os testes individuais de significância para os parâmetros $\lambda$ e $\sigma$ apresentam resultados semelhantes.
} 
Como mostram os testes conjuntos, a possibilidade de saltos é extremamente importante para explicar os preços dos derivativos e, portanto, deve ser incluída na estimação. Os valores encontrados para o parâmetro $\sigma$, utilizando-se a fórmula de Merton, podem ser vistos como estimativas implícitas da volatilidade da taxa cambial controladas pelas variáveis $k, \sigma j$ e $\lambda$.

As estimativas de $\sigma$ obtidas (em torno de $1 \%$ e nunca superiores a $5 \%$ ) são bem menores que as volatilidades implícitas encontradas usualmente nas opções de câmbio utilizando-se um modelo da família Black \& Scholes (entre 15\% e 30\% para as opções mais "fora do dinheiro" como mostra a figura 1. 17 Essa diferença se deve à inclusão da possibilidade de saltos no processo de difusão. Como é possível perceber pela figura 4, as estimativas de $\sigma$ implícitas nos preços das opções de acordo com o modelo de Merton são bastante próximas das calculadas a partir de séries temporais no mercado de dólar à vista. Além de terem ordens de grandeza semelhantes, os movimentos das duas séries são correlacionados. ${ }^{18}$

Figura 4

Volatilidade histórica X implícita

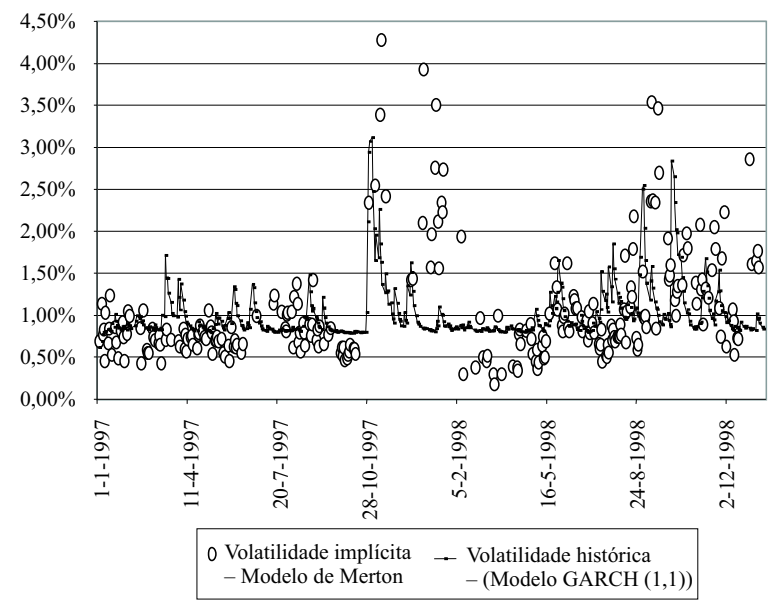

\footnotetext{
${ }^{17}$ Nos dias em que apenas opções fora do dinheiro foram negociadas, a volatilidade é sempre insignificante do ponto de vista estatístico porque o prêmio das opções com preços de exercício mais altos é dado apenas pela combinação entre os parâmetros $\lambda_{t}, k$ e $\sigma j$, ou seja, é determinado unicamente pelo risco de um salto discreto.

${ }^{18}$ A série histórica de volatilidade foi calculada estimando-se um modelo GARCH( 1,1$)$. No caso da volatilidade obtida implicitamente, só foram plotados os valores estatisticamente significativos.
} 
Nas estimativas de volatilidade obtidas pelo modelo de Merton, não está incluída a possibilidade de saltos discretos, visto que esta é captada pelos outros parâmetros do modelo $\left(\lambda_{t}, k\right.$ e $\left.\sigma j\right)$. Eliminando-se da "volatilidade" do modelo de Black \& Scholes a possibilidade de saltos, obtêm-se estimativas similares às encontradas pelas análises de séries temporais, sem necessidade de variação do $\sigma$ de acordo com o preço de exercício. Temos, agora, bons argumentos para afirmar que os possíveis impactos de uma alteração no regime de bandas cambiais estavam sendo mimetizados pelos smiles de volatilidade.

\section{A credibilidade do regime cambial}

Vários estudos (como Munch (1998), Campa et al. (1999) e Fontes et al. (1999)) tentam avaliar a confiabilidade na política cambial a partir de testes de credibilidade aplicados à banda larga. Contudo, como mostra a figura 5, esta não caracterizava completamente o regime vigente no período. Na prática, a taxa de câmbio era desvalorizada em torno de $0,6 \%$ ao mês e poderia mover-se apenas entre os estreitos limites das minibandas (de cerca de $0,5 \%$ na maior parte do período) ditados pelo Banco Central. Assim, não parece ser muito adequado julgar a credibilidade da política testando a banda larga.

Figura 5

Trajetória da taxa de câmbio

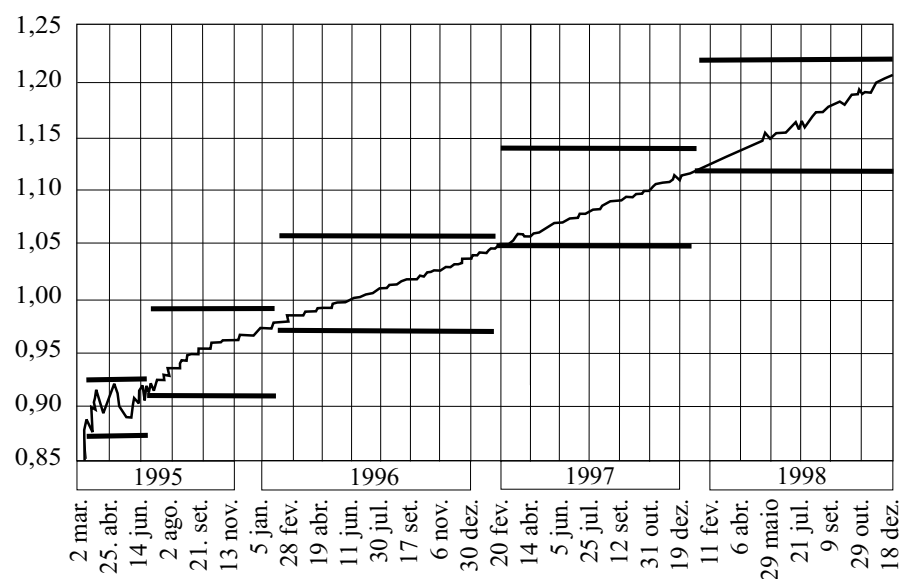

Fonte: Fontes et al. (1999) 
Em um regime de bandas confiáveis, quando a cotação cambial está no limite superior, deve-se esperar uma queda da taxa de câmbio - propriedade chamada de reversão à média. No caso em estudo, porém, em nenhum momento deveria ser esperada uma valorização do real, pois a manutenção da política incluía o reajuste periódico da banda larga. Ainda assim, (Fontes et al., 1999) examinam essa propriedade e observam que, de fato, mesmo quando o dólar estava perto do teto da banda larga, sua tendência era de alta. Os autores concluem que esse comportamento "não é coerente com a teoria de bandas de câmbio para credibilidade perfeita, apesar de ser significativo a 1\%". Ao nosso ver, não há nada de novo nesse resultado e informação alguma sobre a confiabilidade do regime, apenas um sinal da inadequação da aplicação dos testes de credibilidade da banda larga ao regime de câmbio brasileiro vigente no período.

Um dos testes realizados por Munch (1998) e Campa et al. (1999) examina se a cotação do dólar nos mercados futuros ultrapassa em algum momento o limite superior da banda larga. Como mostra a figura 5, nos primeiros meses após os reajustes, a cotação cambial está bastante distante do teto da banda larga. Nesses momentos, o fato de o teto não ser ultrapassado pela taxa futura do dólar diz pouco a respeito da credibilidade das mini-bandas e eram estas que desempenhavam, de fato, o papel principal na política cambial daquela época.

Como Rocha \& Moreira (1998), entendemos a credibilidade da política de câmbio como uma combinação entre a probabilidade da desvalorização do real e sua magnitude esperada. Além de mais adequada, essa abordagem traz respostas mais precisas à questão da confiabilidade no regime. Afinal, uma banda tem crédito apenas se os agentes consideram que a probabilidade dela ser rompida é exatamente zero? Se não é zero, qual o número arbitrário que divide as águas? Que valores caracterizam uma credibilidade "perfeita" ou "imperfeita"?

Evidentemente, a probabilidade atribuída pelos agentes à alteração na política cambial no Brasil durante o período estudado era diferente de zero. Neste artigo, tentamos quantificar essa percepção de confiabilidade. Além disso, a metodologia empregada não visa à simples estimação do prêmio de risco implícito nos contratos futuros de câmbio como se esta fosse uma variável unidimensional, mas traz informações a respeito das probabilidades e magnitudes esperadas da desvalorização cambial.

As alterações diárias no parâmetro $\lambda$ refletem os momentos de "nervosismo" e "calmaria" no mercado financeiro. Acreditamos que esta variável, associada à média e ao desvio-padrão da distribuição de probabilidades do salto, seja um bom indicador da credibilidade da política cambial. A volatilidade do componente 
de salto e a esperança não-condicional do valor dos saltos $(\lambda \times k)$, podem ser boas proxies para a desconfiança na moeda.

A figura 6 mostra a evolução da volatilidade do componente de salto durante os dois anos cobertos por este artigo. Nos gráficos, cada figura geométrica corresponde a um vencimento de opção.

Figura 6

Volatilidade do componente de jump

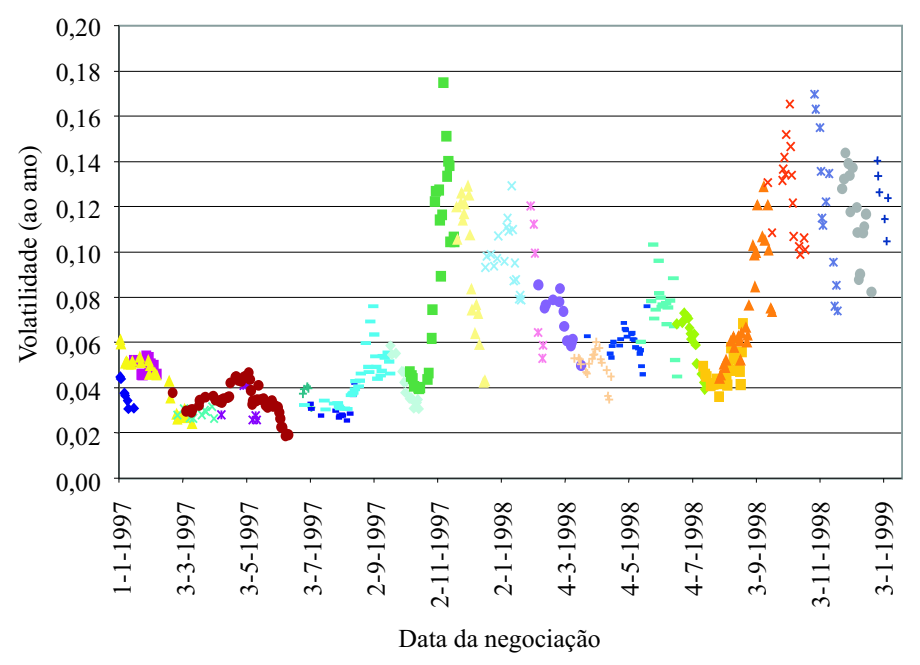

A esperança não-condicional do valor dos saltos $(\lambda \times k)$ é uma medida do prêmio de risco implícito nos contratos futuros. ${ }^{19}$ Cabe, então, compará-la com o prêmio de risco dos contratos futuros de câmbio observado ex post, dado pela diferença entre o dólar futuro em um dado momento e a taxa cambial spot no dia do vencimento do derivativo. ${ }^{20}$

\footnotetext{
${ }^{19}$ Veja a equação de difusão do modelo de Merton: essa esperança é justamente a diferença entre o diferencial de taxa de juros $(b)$ e o drift esperado (o fator que multiplica $d t$ ).

${ }^{20} \mathrm{O}$ prêmio de risco ex post dos contratos futuros foi calculado a partir da seguinte fórmula: $\left.\operatorname{Prfut}=\left(\left(F_{t} / S_{t+\tau}\right)-1\right) / \tau\right)$ onde: $F_{t}$ é o valor do contrato futuro de dólar em $t ; S_{t}+\tau$ é o valor do dólar spot no dia do vencimento do futuro; $\tau$ é o tempo até o vencimento do futuro. A divisão por $\tau$ é feita para que seja obtida uma medida anualizada do prêmio de risco.
} 
Figura 7

Esperança não-condicional de jump(implícita, por ano)

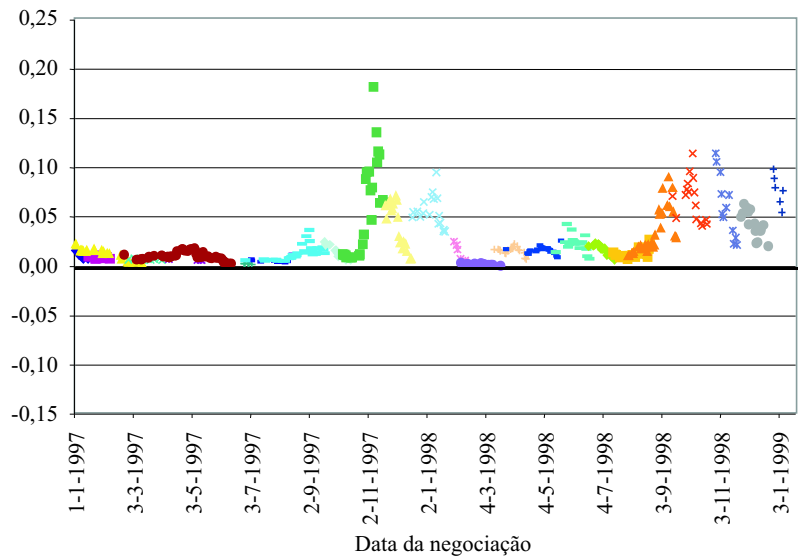

Figura 8

Prêmio de risco do dólar futuro (ex post, anualizado)

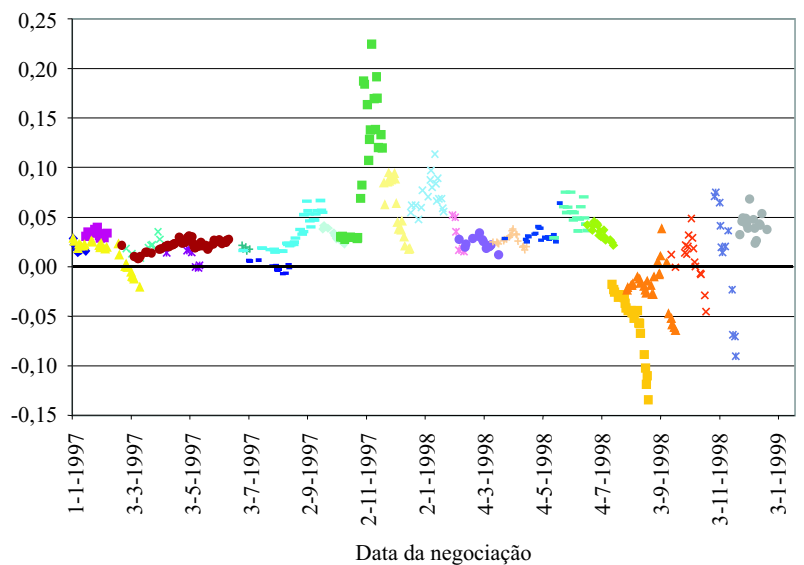

Os gráficos das figuras 7 e 8, construídos na mesma escala para facilitar comparações, nos mostram que há muitas semelhanças entre parte dos gráficos, mas que no segundo semestre de 1998 a discrepância é enorme. Em particular, em boa parte dos momentos em que o mercado enfrentava os reflexos da crise russa, o gráfico construído a partir do prêmio observado ex post parece indicar um sério risco de apreciação do real! Qual a explicação para isso? 
O modelo de Merton nos ajuda a encontrar essa explicação ao dividir as flutuações cambiais entre as oscilações causadas por uma volatilidade $(\sigma)$ e os saltos discretos $(J)$. O fato de encontrarmos um prêmio de risco negativo ex post, num dado dia $t$, significa apenas que a cotação do dólar no dia do vencimento do contrato futuro estava acima do valor deste em $t$. Isso não mostra que o mercado considerasse a possibilidade de uma apreciação cambial: à luz das nossas estimativas de parâmetros implícitos, o que se pode concluir num caso deste é que o fator volatilidade foi responsável por deixar o dólar spot próximo ao topo da minibanda no dia do vencimento do futuro, mas o prêmio de risco era mesmo positivo. De fato, entre agosto e dezembro de 1998, a taxa cambial nos dias de vencimento dos contratos futuros (último dia do mês) ficou muito próxima do teto da minibanda. Por outro lado, no período em que foram sentidos os efeitos da crise asiática (entre outubro de 1997 e início de 1998), o dólar esteve próximo do piso da minibanda no final desses meses. ${ }^{21}$

Essa explicação e os resultados mostrados pelos gráficos nos levam a acreditar que estimar o prêmio de risco como foi feito neste artigo (figura 7), a partir de parâmetros implícitos, conduz a resultados melhores que o cálculo ex post pela diferença entre o valor dos futuros e do spot no vencimento (figura 8), justamente por separar os dois componentes responsáveis pelas oscilações cambiais (a volatilidade e os saltos).

Deve-se, porém, prestar atenção às imperfeições das estimativas obtidas: nem todos os parâmetros estimados são estatisticamente significativos e, portanto, os gráficos devem ser interpretados com cautela. Além disso, eventuais intervenções do Banco Central no mercado futuro de câmbio podem estar interferindo nos preços dos contratos e, conseqüentemente, nos parâmetros estimados. Por fim, deve-se ter em mente que os valores de probabilidade e de magnitude da desvalorização esperada se referem a prazos bastante curtos, visto que, na maior parte dos casos, as opções vão ganhando liquidez a partir de 45 dias antes do vencimento. A viabilidade da política cambial no longo prazo não aparece diretamente nestes resultados $^{22}$.

A pergunta que os gráficos estão respondendo é: "qual a expectativa do mer-

\footnotetext{
${ }^{21}$ Como mostram os gráficos e as explicações de Pastore \& Associados (1999), "devido aos menores fluxos de saída no comercial, a taxa spot esteve muito menos pressionada na crise do sudeste asiático do que na crise russa. As cotações do câmbio comercial somente atingiram o topo da [mini] banda por alguns dias, em outubro de 1997, enquanto que na crise russa as cotações estiveram predominantemente no topo da [mini] banda de flutuação".

${ }^{22}$ Isto significa, por exemplo, que se o mercado passar a acreditar que a trajetória do câmbio será alterada dali a seis meses, mas não antes disso, nossos valores não mostrarão essa queda de credibilidade da política.
} 
cado com relação a alterações na política cambial nas próximas semanas?". Podemos ver que esta expectativa aumenta bruscamente quando a crise asiática contagia os mercados brasileiros, em outubro de 1997, e vai aos poucos se reduzindo. Já no começo de 1998, os agentes passam a acreditar que a chance de uma grande desvalorização no curto prazo é muito menor — talvez pela proximidade das eleições presidenciais. Antes destas, porém, em setembro de 1998, sentem-se os efeitos da crise russa e, novamente, cresce a expectativa de um salto na cotação cambial. Tal expectativa não se dissipará até o início de janeiro, quando ocorre efetivamente a ruptura da trajetória do dólar. As estimativas obtidas mostram que a queda de confiança na moeda trazida pela crise na Rússia foi mais persistente que a resultante da crise do Sudeste asiático (talvez pela passagem das eleições), resultado corroborado pelas análises conjunturais da época (Pastore \& Associados, 1999).

Além desses grandes fatos estilizados, podemos perceber outros movimentos mais sutis, como a redução do medo da maxidesvalorização em meados de fevereiro de 1997 (quando houve a mudança da banda larga) ou os primeiros reflexos da crise asiática em agosto de 1997. Os gráficos também não mostram um aumento da desconfiança no real nas semanas imediatamente antecedentes ao salto do dólar. Muito embora esse resultado possa parecer estranho, deve ser lembrado que o governo brasileiro fechou um acordo com o FMI no final de 1998 e análises macroeconômicas da época apontavam para uma melhora na credibilidade do regime. Por exemplo, a Carta de Conjuntura do Ipea (1998) afirma que "a pressão sobre o câmbio tornou-se mais branda, sendo agora bem pouco provável a ocorrência de um ataque especulativo".

As figuras 6 e 7 mostram claramente a percepção do risco de desvalorização do real flutuando conforme a situação de outros países emergentes, evidenciando a importância de fatores relacionados a contágio para explicar fatos como ataques especulativos.

\section{Conclusão}

Os testes conjuntos dos parâmetros referentes à possibilidade de saltos $(\lambda, k \mathrm{e}$ $\sigma j$ ) e os valores da volatilidade implícita $(\sigma)$ estimada pelo modelo de Merton evidenciam que os smiles de volatilidade mimetizavam a possibilidade de ocorrência de saltos discretos. Há um problema de identificação nas estimações realizadas, que compromete um pouco os resultados individuais dos parâmetros, mas não altera em nada essa conclusão.

Uma das vantagens do modelo de Merton é fornecer parâmetros com interpretação econômica imediata. A partir dos valores estimados de $\lambda, k \mathrm{e} \sigma j$, foram 
traçados mapas da credibilidade de curto prazo da política cambial em vigor no período, tentando contribuir na avaliação da confiabilidade do regime.

Mostrou-se, também, que a magnitude da desvalorização ocorrida efetivamente em janeiro de 1999 parece ter sido diferente da projetada pelos prêmios das opções. Se o tamanho do salto cambial dado em janeiro não foi uma realização muito improvável de sua distribuição de probabilidades, os preços dos derivativos não incorporaram corretamente a magnitude da desvalorização cambial.

Há algumas extensões possíveis para o trabalho apresentado neste artigo: a primeira delas consiste em verificar, no caso da taxa cambial brasileira no período estudado, se o salto é bem-descrito por uma distribuição de probabilidades lognormal e se outra distribuição seria mais adequada. Campa et al. (1999) estudam o mercado de câmbio brasileiro de 1994 a 1997 sem impor nenhuma distribuição de probabilidades para os retornos, a partir de estimações não-paramétricas. Este pode ser um caminho para as respostas a essas questões.

Após o salto da cotação cambial em janeiro de 1999, observou-se uma ruptura na política antiga e o fim da camisa-de-força sobre o antigo processo de difusão, enquanto o modelo prevê continuidade e a possibilidade de novos saltos a qualquer momento. Talvez seja uma boa opção trabalhar com um processo de difusão que considere a possibilidade não só de um salto na cotação do câmbio, mas de uma ruptura na trajetória.

Seria interessante, também, estender a análise para o período posterior à mudança do regime cambial. Será que a possibilidade de saltos continua sendo um importante componente nos preços dos derivativos?

Este artigo aponta a possibilidade de saltos discretos como uma causa para a existência dos smiles de volatilidade no mercado de câmbio brasileiro no período estudado. Cabe, então, a pergunta: será que os smiles observados em outros mercados do país também são causados, pelo menos em parte, pela possibilidade de saltos?

\section{Referências}

Bakshi, G., Cao, C., \& Chen, Z. (1997). Empirical performance of alternative option pricing models. Journal of Finance, 52(5).

Bates, D. S. (1991). The crash of '87: Was it expected? the evidence from options markets. Journal of Finance, 46(3).

Bates, D. S. (1996). Jumps and stochastic volatility: Exchange rate processes 
implicit in deutsche mark options. The Review of Financial Studies, 9(1):69108.

Black, F. \& Scholes, M. S. (1973). The pricing of options and corporate liabilities. Journal of Political Economy, (81):637-59.

Campa, J. M. et al. (1999). An options-based analysis of emerging market exchange rate expectations: Brazil's real plan, 1994 - 1997. Working paper, 6929, NBER.

Davidson, R. \& MacKinnon, J. G. (1993). Estimation and Inference in Econometrics. Oxford University Press.

Fontes, R., Arbex, M. A., \& Almeida, M. (1999). Credibilidade perfeita versus credibilidade imperfeita: Uma análise para o regime brasileiro de bandas de câmbio. Pesquisa e Planejamento Econômico, (29):185-214.

Guimaraes, B. V. (2000). A possibilidade de saltos discretos no câmbio implícita nos prêmios das opções (jan/97 a jan/99). mimeog, USP. (Dissertação de Mestrado em Economia).

Ipea (1998). Carta de conjuntura.

Merton, R. C. (1976). Option pricing when underlying stock returns are discontinuous. Journal of Financial Economics, (3):125-44.

Munch, I. P. (1998). Bandas de câmbio e expectativas de desvalorização: Um teste de credibilidade aplicado ao brasil, méxico, rússia, venezuela, tailândia e hong-kong. Revista Brasileira de Economia, (52):637-73.

Pastore, A. C. \& Associados (1999). Os riscos do programa brasileiro de ajustamento. Capturado em: http://www.acpastore.com/publicacoes/Relatorios /Janeiro99.pdf.

Rocha, K. M. C. \& Moreira, A. R. B. (1998). Credibilidade da política cambial e as opções cambiais. Pesquisa e Planejamento Econômico, (28):509-29. 


\section{Anexo A}

\section{Estimativa do parâmetro $\lambda$}

O parâmetro $\lambda$ de uma distribuição de Poisson deve ser interpretado como a taxa de ocorrência de um evento (no caso, um salto). Nos gráficos das figuras A.1 a A.4, $\lambda$ é dado em termos anuais. As estimativas obtidas, porém, dizem respeito a horizontes menores, como um mês.

Assim, $\lambda=0,6$ (ao ano) corresponde a uma taxa de $5 \%$ ao mês, implicando que a probabilidade de um salto em 30 dias corridos é de $4,76 \%$ e a probabilidade de dois saltos no mesmo período é de $0,11 \%$. Um $\lambda=0,3$ (ao ano) corresponde a uma taxa de $2,5 \%$ ao mês, probabilidade de um salto igual a $2,44 \%$ e uma probabilidade de dois saltos de $0,03 \%$. As probabilidades de mais de um salto são sempre pequenas.

No exemplo da figura A.1, as opções vencem no primeiro dia de fevereiro. Portanto, os parâmetros referem-se à chance de desvalorização cambial em períodos de 20 a 35 dias. Poucos dias antes da maxidesvalorização, a probabilidade estimada de um salto do dólar era de cerca de $5 \%$ ao mês.

Figura A.1

Parâmetro $\lambda$ (vencimento em fev. 1998)

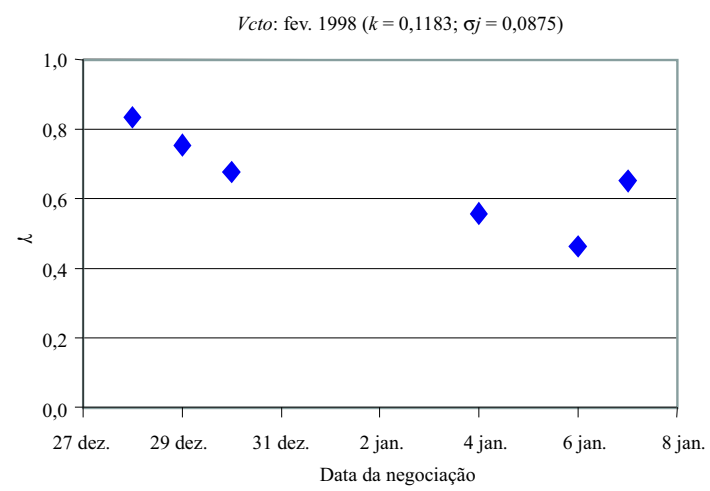

Os gráficos para todos os vencimentos (figuras 10 a 12) foram construídos na mesma escala vertical para facilitar comparações (mas as escalas horizontais são diferentes). 
Figura A.2

Estimativas do parâmetro $\lambda$ (vencimentos em fev. 1997 a set. 1997)
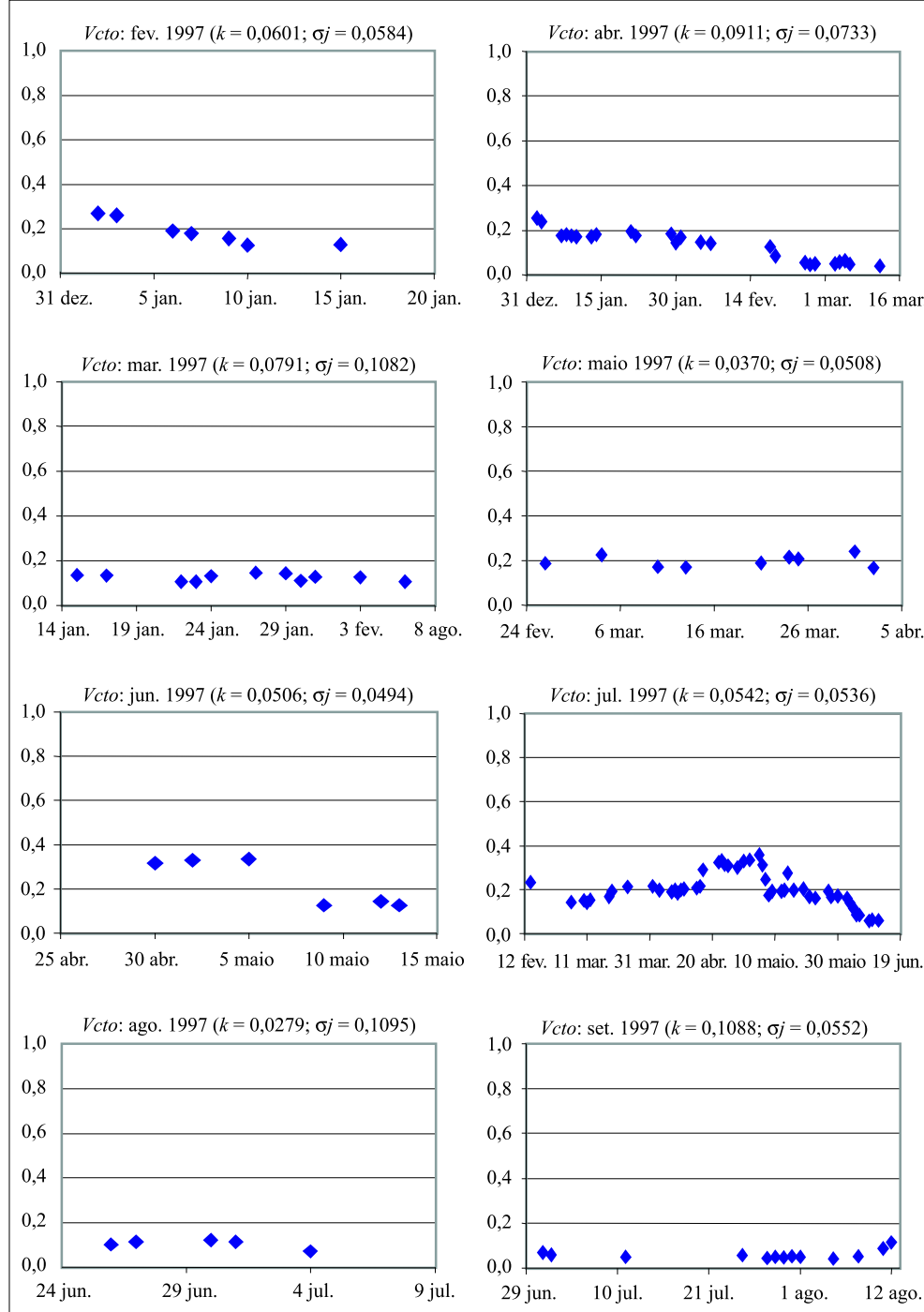
Figura A.3

Estimativas do parâmetro $\lambda$ (vencimentos em out. 1997 a maio 1998)

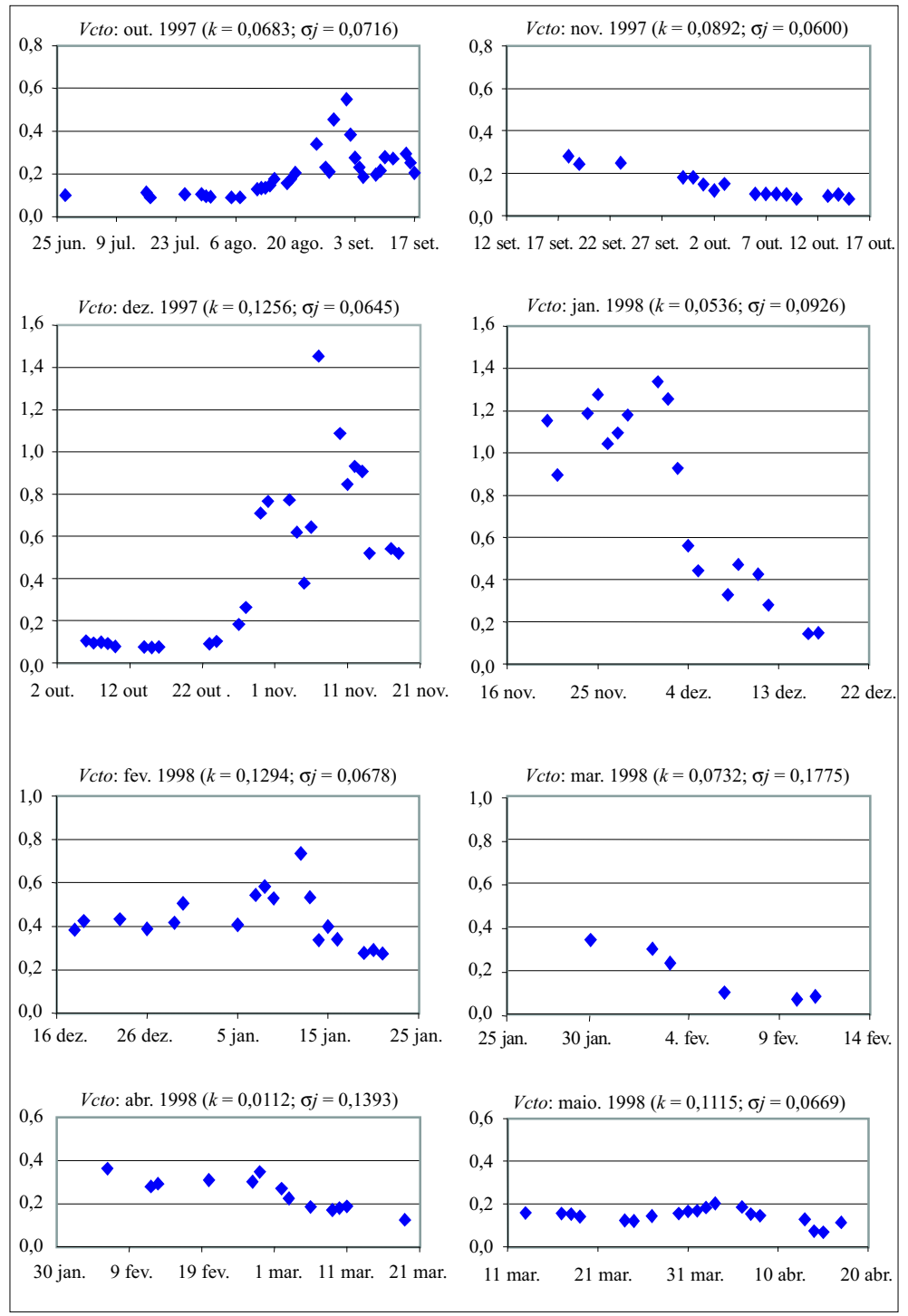


Figura A.4

Estimativas do parâmetro $\lambda$ (vencimentos em jun. 1998 a jan. 1999)
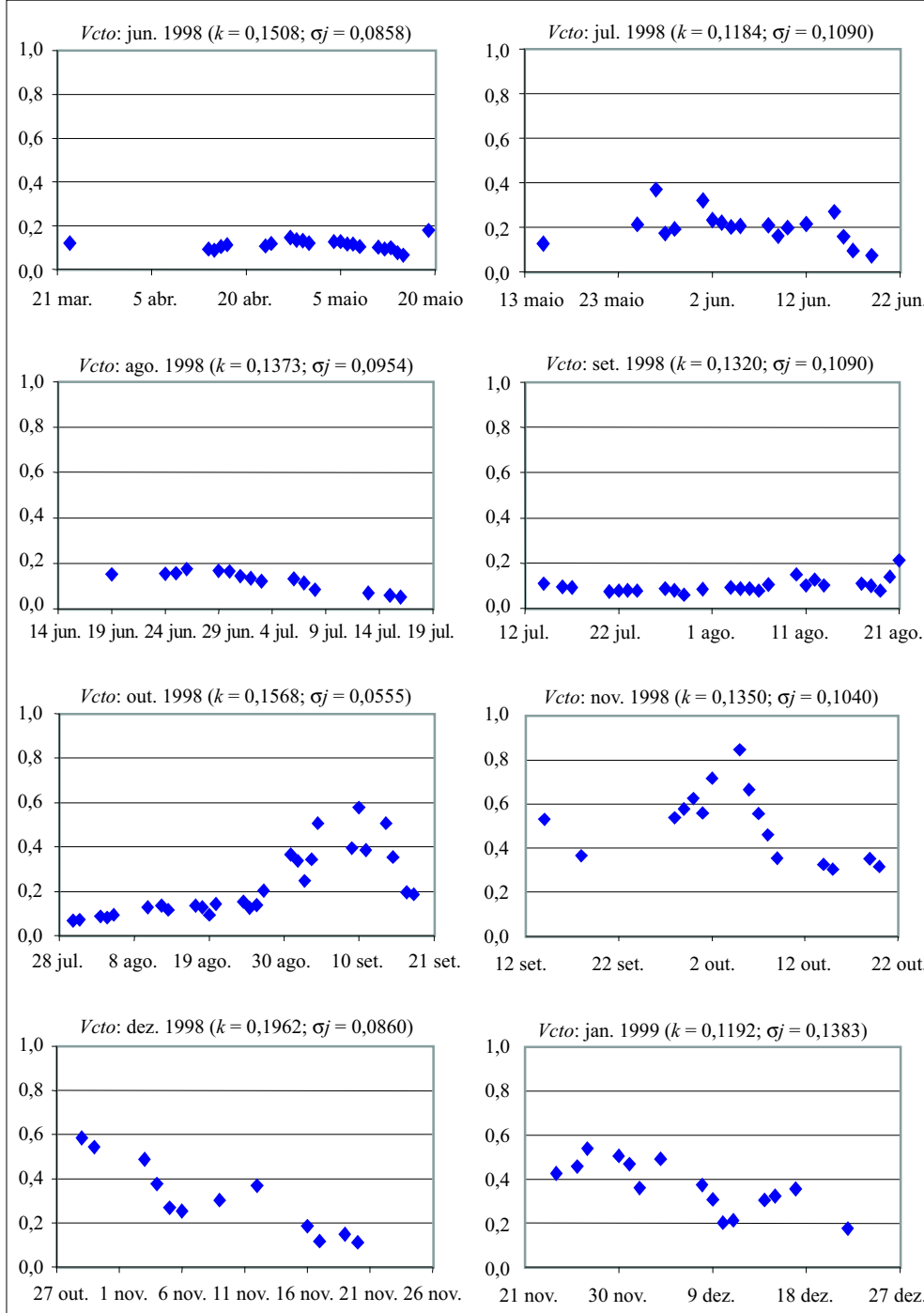


\section{Anexo B}

\section{Influências de variações não-controladas da volatilidade}

Os parâmetros $k$ estimados pelo modo 2 são usualmente menores que os encontrados pelo modo 1. Este anexo busca mostrar que essas diferenças podem ser causadas por variações não-controladas da volatilidade. O argumento baseia-se em um experimento de Monte Carlo. Fixando-se os parâmetros $\lambda, k$ e $\sigma j$ e variando-se $\sigma$ diariamente, estimou-se o modelo de Merton de acordo com o modo 2 (apenas uma volatilidade foi estimada).

A base de dados foi composta por seis observações diárias em 15 dias (resultando em 90 pontos na amostra). O vencimento em agosto de 1998, escolhido como base para o experimento, forneceu os valores de $S$ (cotação do dólar à vista) e $\tau$ (tempo até o vencimento). Foram utilizados os seis preços de exercício mais líquidos desse vencimento. Por simplicidade, escolheu-se $r=20 \%$ (taxa de juros interna) e $b=10 \%$ (diferencial de juros).

Os parâmetros utilizados na simulação foram: $k=0,14 ; \sigma j=0,09$ e $\lambda=0,20$. Supôs-se uma volatilidade distribuída uniformemente entre $0,5 \%$ e $1,5 \%$, ou seja: $\sigma \sim U(0,005 ; 0,015)$. Por fim, considerou-se que os preços das opções eram dados por:

$$
\operatorname{PMerc}_{x t}=\operatorname{PMod}{ }_{x t}\left(S_{t}, b_{t}, r_{t}, \tau_{t}, X, k, \sigma j, \sigma_{t}, \lambda_{t}\right)+\epsilon_{x t}
$$

sendo $\epsilon_{x t}$ distribuído normalmente com média zero e desvio-padrão igual a 0,02 (valor aproximado do desvio-padrão dos erros estimado para o vencimento em agosto de 1998).

Em cada uma das 100 repetições, foram calculados os valores das 90 opções (com 15 volatilidades aleatórias e independentes). Então, estimou-se o modelo de Merton pelo modo 2, obtendo-se, assim, 100 estimativas de $k, \sigma j$ e $\sigma$ e 100 vetores com 15 valores de $\lambda .{ }^{23}$ Os resultados obtidos estão apresentados na tabela B.1, sendo $\Lambda$ o valor médio das estimativas diárias de $\lambda$ em cada uma das 100 simulações. Os testes $t$ realizados (bilaterais) verificam se a esperança dos estimadores de $k \mathrm{e}$ $\Lambda$ são significativamente diferentes de 0,14 e 0,20 , respectivamente.

\footnotetext{
${ }^{23}$ Devido ao alto custo computacional envolvido, não foram mudadas as condições iniciais no algoritmo de otimização - o que significa que alguns dos mínimos encontrados podem não ser globais.
} 
Tabela B.1

\begin{tabular}{ccccc}
\hline Variável & Média & $d p$ & t-stat & p-value \\
\hline$K$ & 0,1141 & 0,0362 & $-7,133$ & $1,6 \times 10^{-10}$ \\
$\Lambda$ & 0,2488 & 0,0603 & 8,055 & $1,8 \times 10^{-12}$ \\
\hline
\end{tabular}

Como mostra a figura 4, as alterações na volatilidade não são tão constantes como supõe esse experimento. Ainda assim, mesmo com a existência das minibandas, podemos perceber alterações no parâmetro $\sigma$. De fato, o intervalo de $0,5 \%$ para a flutuação de câmbio é pequeno na análise do economista, mas é equivalente a um prêmio de risco de $6 \%$ ao ano em um contrato de câmbio futuro com vencimento em um mês. Portanto, os impactos no preço dos derivativos de mudanças nas expectativas com relação aos fluxos cambiais de curto prazo devem resultar em variações significativas no preço, captadas pelo parâmetro de volatilidade.

Assim, faz sentido acreditar que as estimativas de $\lambda$ e $k$ são contaminadas por alterações não-controladas na volatilidade, mas a magnitude desse viés deve ser menor do que a obtida neste experimento. 